\title{
13 Forced car ownership and forced bus usage
}

\author{
Contrasting realities of \\ unemployed and elderly people \\ in rural regions - the case of \\ Guarda, Portugal
}

Vasco Reis and André Freitas

\begin{abstract}
This chapter explores the results of fieldwork activities targeting elderly and unemployed people living in Guarda, Portugal. Most of these citizens use a car, even if the former recognise that they are not fit enough to drive and the latter bear high costs. However, both groups perceive these efforts as fulfilling a basic need of living in such a rural and mountainous region where local authorities prefer to focus on urban citizens. Toll costs are regarded as a major barrier for unemployed people to get to work in territories where job opportunities are scarce, whereas elderly citizens, particularly those living in isolated places, are "forced" to use the bus and struggle with operational PT inadequacies.
\end{abstract}

\section{Contextualisation}

The fieldwork conducted in 2018 and 2019 focused on a region in the northeast of Portugal, more precisely on Guarda, the largest city in the district with the same name (Figure 13.1).

Guarda is a municipality of 42,500 inhabitants (the city of Guarda alone has about 26,500 inhabitants) scattered across a territory of 712 square kilometres and encompassing 43 smaller districts (Francisco Manuel dos Santos n.d.). Agricultural activities as well as forests cover a mountainous area, with Guarda being the highest city in terms of elevation in continental Portugal (1,056 metres above sea level). The area can be classified as monocentric, with an urban area (that is the city of Guarda) concentrating most employment opportunities, business and industrial centres.

The other main socio-economic characteristics identified by local stakeholders interviewed during the fieldwork are:

- Remote rural settlements, inhabited by middle-aged and elderly people, whilst the younger population dominates the main city of Guarda; 


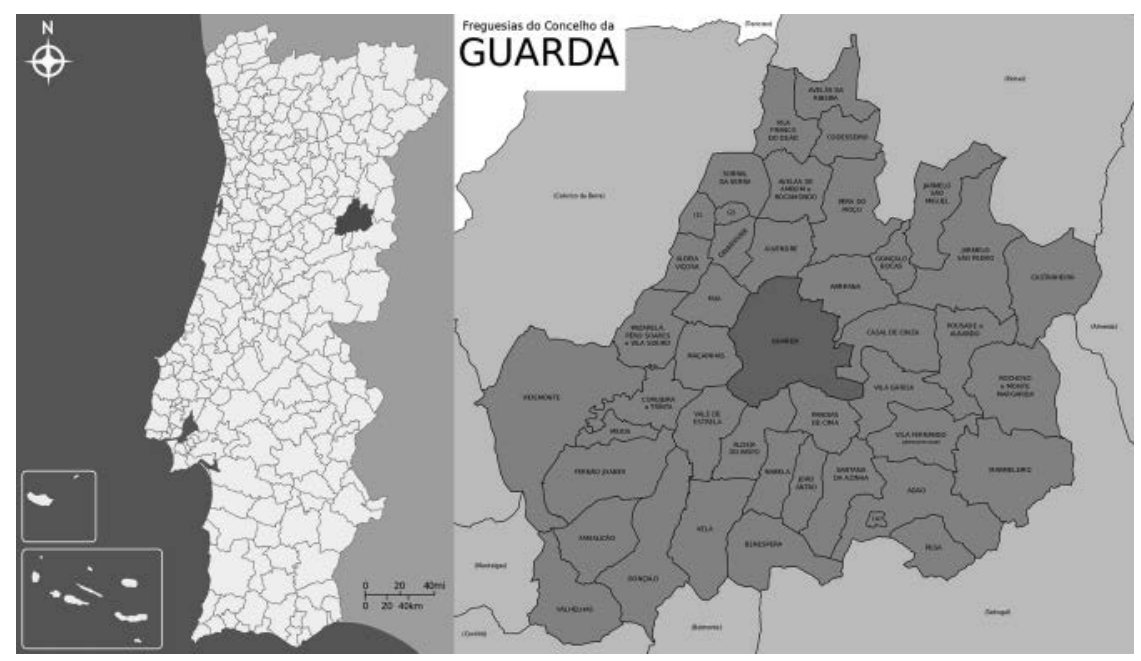

Figure 13.1 Map with the location of the municipality of Guarda. Source: Wikipedia 2006 (left), TIS (right).

- Some remote-rural settlements have a higher percentage of women mostly living on their own; and

- People living in remote-rural areas tend to have low income and, hence, difficulties to afford a private car. They are often unemployed and make their living from local agricultural activities.

Target groups in this region comprise low income and unemployed people, as well as elderly people. Some of the main indicators concerning these two segments are listed below. In a nutshell, the municipality features higher motorisation rates than the average for Portugal and a much lower share of public transport usage when compared to other national medium-sized cities. The number of older people living in the region is also higher than the national average.

Table 13.1 highlights some key indicators for Guarda compared to the national average. The figures can be understood as a token of the current and future risk to social vulnerability that affects this area.

Guarda features a railway station, which is about three kilometres away from the city centre. It includes a small freight terminal and offers international services for passengers to Salamanca and Madrid as well as some domestic services to surrounding towns and to the capital Lisbon.

The region is served by some major motorways, all of which are toll roads. The availability of road infrastructure is acceptable overall, with some settlements being served by small local roads. During rough winter times, some roads are closed due to icy conditions. Public transport frequency from small villages to the city centre is limited to one or two journeys per 
Table 13.1 Key indicators for Guarda compared to the average for Portugal

\begin{tabular}{llcc}
\hline Parameter & Indicator & Guarda & Portugal \\
\hline Transport & Motorisation rate in 2017 & $678.7^{\mathrm{a}}$ & 491.2 \\
& Modal share of public transport in 2011 & 10.8 & 15.9 \\
Elderly people & Old-age dependency ratio in 2018 & 34.8 & 33.6 \\
& Percentage of people above 65 years old & 22.8 & 21.7 \\
& in 2018 & 96.2 & 100 \\
Low income and & Purchasing power per capita in 2017 & 5.4 & 5.4 \\
$\quad$ unemployed & Unemployment rate (\%) in 2018 & 55.2 & 111.5 \\
People living & Population density (per km (n) $^{2}$ in 2018 & & \\
$\begin{array}{l}\text { in rural and } \\
\text { deprived areas }\end{array}$ & & & \\
\hline
\end{tabular}

Source: Official population projections from the National Statistical Institute of Portugal (Instituto Nacional de Estatistica Portugal n.d.).

a According to the national insurance statistics which provide this indicator per municipality (Portuguese Insurance Regulation and Supervision Agency n.d.).

b According to a study about mobility in Portuguese medium-sized cities, carried out by the national transport authority (Seabra 2011).

day and becomes even more limited at weekends and during school holidays. The urban service features five public transport routes. Its taxi service declined over the past few years due to a lack of demand, both in remote settlements and even in the city, at night.

\section{Interviews with stakeholders}

The main policy makers and key stakeholders were selected taking into consideration their level of knowledge of the major transport and social dynamics and, consequently, their level of understanding of the wide spectrum of vulnerabilities felt by the locals in Guarda. ${ }^{1}$ The five interviews involved the following stakeholders:

- The municipality (interviews were organised with traffic and education experts, as well as with the council regarding transport issues in Guarda);

- Guarda's parish presidents;

- The president of social security for the district area of Guarda; and

- A representative of an NGO providing healthcare support and transport for their members.

Even considering the variety of stakeholders, the overall outcome of the interviews is that municipality representatives and experts have no in-depth knowledge about transport needs in the region, especially those concerning the population that is more isolated and those of people with weaker social ties, supported by local associations and NGOs that operate in rural areas. 
Among policy makers, there is great attention towards children's mobility needs, but no other groups' needs. This can be considered a knowledge issue, given that the municipality is assuming new responsibilities as a transport authority. This has forced local stakeholders to take problems more seriously, with greater care, and now vulnerable groups' mobility needs are placed at the top of the political agenda.

In addition to this, most of the existing ongoing initiatives are still urban-centric and designed for the urban citizen. The public transport operator (a privately owned company called Transdev) is not particularly sensitive to the needs of residents in isolated areas, focusing on a traditional, product-driven service, with poor attention to people with mobility impairments. Overall, the design of the public transport system disregards vulnerable groups' mobility needs, considering them as niche issues. Indeed, there are NGOs taking care of older citizens with reduced mobility, offering a transport service, especially to those living in very remote areas.

Transport stakeholders reported that the number of people who cannot actually fulfil their mobility needs is, however, low and often limited to villages and locations where the public transport service is not available. This also includes neighbourhoods in the city of Guarda, those located on the verge of the city and even without any public transport. Interviews with stakeholders working in social care highlighted a low number of people who are actually suffering from social exclusion. Social care stakeholders suggested focussing on unemployed persons living in sparsely populated areas as well as elderly people living in neighbourhoods on the outskirts of the city. As regards the latter group, it was suggested that people living closer to the city might be less physically isolated but more disconnected and socially isolated than those located in small villages.

\section{Overview of focus groups: occurrences of mobility poverty}

As a second stage of the fieldwork, two vulnerable segments were selected for the focus group activities: low-income and unemployed, on the one hand; and elderly people, on the other. For both groups, special attention was paid to those living in areas with limited public transport options.

\section{Unemployed people}

The focus groups revealed that unemployed people make a fairly high number of daily trips, even if the literature and especially the work carried out by Karen Lucas and colleagues have shown that the general category of people on low income tend to be much less mobile (e.g. Lucas 2012). This reasoning led one to assume that unemployed people could adapt their mobility options because they do not have regularly fixed appointments, as they are not employed. However, during the focus groups, it turned out that the 
unemployed people of Guarda do not use public transport at all, not even occasionally. In fact, according to official figures there is a high percentage of unemployed people who use local public transport, but in the focus groups it was not possible to interact with anyone who uses this mode of transport in the region. When asked about the reasons behind such non-use, in their view the local public transport service was of little help, expensive and unfit for people's needs.

Even though they do not currently use local public transport, participants recognise that they used to take such services when they were younger. As they perceived this experience as negative and because the service is becoming poorer and more limited, they even prevent their children from using it, picking them up from school so that they can avoid wasting time waiting for the bus to arrive.

When unemployed people need to make long-distance trips, interviewees mostly use rail services because a car would be too expensive and they would have to pay the toll. Toll costs are regarded as a major difficulty in moving beyond the city limits, a bottleneck for people living in remote regions where job opportunities are scarce. To overcome this barrier (and bearing in mind that public transport does not provide convenient options), participants advocate that toll costs should be different according to people's residence, allowing discounts for permanent residents.

The issue of long-distance trips is particularly important among this group. When seeking new job opportunities, they always bear in mind the costs related to transport because they are aware that extra costs besides fuel will be incurred (such as tyre maintenance). During the sessions, it was reported that some job opportunities were not accepted due to the travel costs involved. Indeed, when looking for new job opportunities, there has been a consensus among the attendees about the willingness to remain within a 40-minute journey time by car from home. Beyond that distance, total transport costs are too financially burdensome and the national minimum wage (580.00 euro) will not cope with these expenses. It was also reported that people increased this range due to a lack of job opportunities in the region (and thus accept higher transport costs which push people into cutting other budget streams for their household).

Needless to say, transport budget restrictions are a key issue for unemployed people who have limited financial resources. Nevertheless, transport - and most notably the car, perceived as the most important mode of transport - is an indispensable utility which is regarded as being of utmost importance and deserving a lot of attention. Some participants emphasise that this is the reason why they devote about $20-25 \%$ of their available income to car-related expenses, whilst others "prefer not to think about it, because it is really a need". It was thus made clear that unemployed people living in remote, peripheral or deprived areas often have to rely on private vehicles to access essential services, posing a substantial financial burden on their households. 
Mobility needs are not limited to accessing services and job seeking, nor to other essential trips. This group of people, even if they have some material deprivation, show a great need to meet with friends and family, even if these friends and relatives live far away. However, on these occasions, the younger representatives of the unemployed group usually share their car with friends because there is no other cheap option to travel across districts, especially at night. As the use of the car severely impacts their available budget, some constraints arise. In order to guarantee mobility, they cut expenditure on other necessities. In fact, the younger participants said that they would like to go to the municipal swimming pools during winter and to the gym as well, but they can't because they cannot afford it.

As mentioned above, interviewees have strongly pointed out that public transport does not fit their needs, neither its schedules nor its frequency. This pushes them to keep a car as their dominant and only transport mode. Such a situation is considered to be without alternatives: during the focus group, participants were asked to identify barriers to using public transport and what their ideal alternative transport mode would look like. However, they had serious difficulties in answering this, bearing the current public transport service in mind.

It is also worth mentioning that the group of unemployed people has a very keen interest in new technologies and uses them abundantly, with the exception of the older members of the group. It was mentioned that the internet can create a sense of proximity, especially felt among those who live in isolated villages. In remote areas, where there isn't even a grocery shop, they shift to online shopping (even if the bandwidth speed is slower than the one being offered in more densely populated areas). This has decreased the need to visit shops to buy goods.

Unemployed people who live in small and remote villages and don't own a car have to count on their social network. They reported that almost everyone knows a relative or friend who owns a car and who is able to help solve minor transport issues. Due to poor public transport services, people, especially from remote villages, are willing to walk up to a four-kilometre distance. If the distance is greater, they routinely ask for car-pooling with their neighbours. In this sense, the lack of transport options could contribute to increasing their ties with the entire community.

To sum up, the main contribution of mobility poverty to social exclusion stems from limiting access to new jobs. In rural regions, where job vacancies are scarce, there is a need to be willing to carry out longer trips which come with a cost, especially if involving the need to pay highway tolls. Those who live in small remote villages also complained that few services remain intact, which is a disadvantage when compared to someone who lives in a city, although the impact is offset by internet access.

\section{Elderly people}

Whilst the unemployed group was more consistent in terms of its social characteristics, the elderly group was not. Elderly people who participated 
in the focus group can be described as having a mix of social characteristics. It became evident from their testimonials that those who live closer to the city centre seemed to have more cultural skills than those who live in the remote villages and have lived there all their lives.

During the focus groups, we noticed that the distance to the city centre is a proxy indicator of educational attainment among the elderly group, whereby those who are closer to the city show higher levels than others who live further away. This is also a disadvantage, especially regarding ICT take-up. Another outcome of the fieldwork is the gender differences among the elderly group, with a remarkable impact on mobility opportunity and choice. We discovered that women drive less than men, are more reluctant to use new technologies and displayed mobility needs, especially those women living in rural areas. On the other hand, a common element is that age reduces older people's ability to drive. In order to maintain an independent way of living, reduced car use makes them more dependent on other people to chauffeur them or to rely on (poor) public transport options.

Currently, most of the mobility needs of older people are met using a private vehicle. Those who do not own a car ask their relatives and friends to pick them up upon request. Sometimes, they use public transport, but very often in combination with a private car and there are a few times, yet more rarely, when they take a taxi. The incidence of mobility poverty is different between areas of the city and between Guarda's districts. It may be that a village is very far away from the main city, but it can still have good public transport connections due to the inter-regional bus network. However, overall, it seems that the participants living in rural areas are poorly served by public transport.

The main mobility complaint for reducing the use of public transport is the inadequate service frequency, often limited to one or two journeys a day. Just adding an extra journey each day, possibly at the end of the morning, may overcome this bottleneck, enabling older people to leave home in the morning, catch a bus to their destination and be back for lunch, instead of waiting for the evening bus. The current limited use of public transport also affects ticket purchasing. The price of a journey is considered too high and a monthly ticket is not always an option, also considering the limited ridership.

Possible solutions for elderly people living in rural villages are therefore quite simple. One solution would involve, first and foremost, activating a more robust public transport service to be used during Guarda's market days. This is something that participants, especially those from rural villages, would warmly welcome because they say that there is an inherited tradition of going there to buy fresh food (and, we would add, to visit the city).

Life-changing events, such as increasing cognitive problems and physical impairments, are severely impacting mobility choices, creating a more or less swift transition from driving to being chauffeured. Even when ageing adversely impacts elderly people, public transport is never regarded as a complete solution due to its strict rigidness and taxis are too expensive for regular use. So, the cornerstone of the mobility solution for people who are 
not fit to drive is a network of social solidarity that can guarantee transport in case of need. In other words, severe ageing and physical and cognitive impairments can hamper mobility, triggering social exclusion. The main counteracting element is a strong social network supporting these people.

Unlike unemployed people, taxis are the last resort, an option for very important and unavoidable appointments. Having said this, it is remarkable that almost all isolated villages do not offer a taxi service nowadays and it was reported that even in the city centre there are no taxis (or for that matter any public transport service) at night, namely after 11 p.m.

Finally, coming back to the digital divide, we noticed a difference in attitude between people living in rural and more urban areas, with the latter being more prone to using digital tools, and this applies to both women and men. Generally speaking, men, especially those who are in their sixties, living closer to an urban area, have already experienced several online interactions, including booking trips. Other groups are not acquainted with the potential of ICT and they also tend to be suspicious about it. Although not mentioned by the focus group participants, interviews with experts have shown that the incidence of mobility poverty is not increasing among the most materially deprived people due to the active role of local associations that already give some responses in terms of mobility needs.

\section{Conclusions from the focus groups}

Elderly people and the unemployed, especially the latter, do not regard themselves as being at critical risk of mobility poverty. However, it is evident that the intensive usage of private vehicles comes with a cost and is made at the expense of other social activities they value and that they are prevented from participating in these due to private vehicle dependency. For some elderly people, most notably those with fewer material resources who live further away from the city centre and the main services, they are forced to adapt to existing public transport services which they use as a last resort.

Both groups have spare time so their daily routines are similar. Those who do not work as farmers have the opportunity to help their families, chauffeuring relatives with whom they live or who live nearby to supermarkets and to different services (such as medical appointments), but also to leisure activities as well. Retired people also use the time they have available to chauffer others in need.

The presence of dense social networks seems crucial to overcoming mobility poverty and to preventing social exclusion. A tight and socially inclusive society can lessen social exclusion even when public institutions do not offer conditions for vulnerable groups to become mobility independent. In fact, considering the high costs that they have mentioned spending on their cars (accounting for almost a quarter of available income for the unemployed group, to give a vivid example of tight dependency), we can thus 
imagine that once public subsidies cease, they will start to become quite vulnerable.

The main results and policy implications can be summarised as follows:

- Guarda is described by both groups participating in the focus groups as a car dependent community. The main social and economic facilities are concentrated in the city centre and others, such as a popular retail park and the university, are located in areas that can hardly be accessed other than by car. On the other hand, the majority of the population is dispersed across the territory. Such a mismatch is connected by car use and overuse so those who do not have access to it experience unmet mobility needs. This mobility poverty increases with age.

- There is a shared feeling among the elderly and unemployed that public transport lacks proper investment. Buses operating in the region are depicted as those not suitable for other European cities and relocated to Guarda at the end of their lifecycle. This can trigger vulnerable groups to move to a larger city.

- Long-distance trips are particularly important among the unemployed. When seeking new job opportunities, they always bear in mind the costs related to transport. Indeed, long-distance travel is increasingly becoming a crucial prerequisite in contemporary employment (and consequently crucial to becoming employed) and disadvantages those unable to conduct physical travel frequently.

- Segments are not homogeneous and feature some important differences. Elderly people, in particular, have completely different mindsets depending on where they live, their age and cultural background. These differences matter in terms of mobility poverty. In general, elderly people living in deep rural and peripheral territories have to face increasing mobility problems, as their public transport offer is limited. They are quite worried about the prospect of needing a (poor or non-existent) public transport service, becoming dependent on it once they become unfit to drive.

- All in all, the phenomenon of forced car ownership was confirmed in Guarda. However, so far, the vulnerability of those without a car is compensated by strong social links and old and new purchase services. This boils down to itinerant vendors (travelling from village to village on designated days) as well as the increased role that online purchasing plays in this field.

All focus group participants recognise that changing mobility habits is not straightforward and requires time. Yet, they would welcome new mobility schemes provided that there are fewer rigid and more flexible public transport services, suitable to their irregular needs and flexible payment options (on subscription for example, rather than fixed monthly passes), taking into account their current socio-economic status. 
Reference to the main statistical data: National Statistical Institute of Portugal (Instituto Nacional de Estatistica Portugal n.d.)

\section{Note}

1 Please see the introduction to this volume regarding the contextualisation and methodology of this research.

\section{References}

Francisco Manuel dos Santos Fundação. n.d. "Base de Dados Dos Municípios." https://www.pordata.pt/. Accessed 3 April 2020.

Instituto Nacional de Estatistica Portugal. n.d. "Statistics Portugal." National Statistics Portugal. https://ine.pt/xportal/xmain?xpgid=ine_main\&xpid=INE. Accessed 3 April 2020.

Lucas, Karen. 2012. "Transport and social exclusion: Where are we now?" In Transport Policy 20: 105-113. https://doi.org/10.1016/j.tranpol.2012.01.013.

Portuguese Insurance Regulation and Supervision Agency. n.d "Insured vehicle statistics." https://www.asf.com.pt/NR/exeres/7D383D46-9431-416E-98C7-395B0 A9E7080.htm. Accessed 3 April 2020.

Seabra, Maria Isabel Carvalho. 2011. Mobilidade Em Cidades Médias. http://www. imt-ip.pt/sites/IMTT/Portugues/Observatorio/Relatorios/MobilidadeCidades Medias/Documents/IMTT_Mobilidade_em_Cidades_Medias_2011.pdf. Accessed 3 April 2020.

Wikipedia. 2006. Distrito de Guarda. Author: Rei-artur. https://commons.wiki media.org/wiki/File:LocalGuarda.svg. Accessed 22 June 2020. 